\section{Is asthma overdiagnosed?}

\author{
Andrew Bush, ${ }^{1}$ Louise Fleming ${ }^{2}$
}

Martin Luther likened human reason to a drunken man on horseback, alternately falling off to the left and then to the right. ${ }^{1}$ The same is true of diagnosing asthma; undoubtedly in the past it was underdiagnosed, but have we gone too far in the opposite direction? The evidence is that we have; for example, in an Australian paper, in which more than 100 children with chronic cough were investigated intensively, including with bronchoscopy (which we do not recommend as a routine diagnostic test!), half were given a diagnosis of asthma prior to investigation; the number actually thought to have asthma had dwindled to $5 \%$ at the end of testing. ${ }^{2}$ Although cough-variant asthma exists, it is overdiagnosed; isolated cough in the community is rarely, if even, due to asthma, ${ }^{3}$ and even in a tertiary centre, atopic children with cough only infrequently have eosinophilic inflammation. ${ }^{4}$ Key to diagnosing asthma correctly is being confident in making that most difficult diagnosis of all, normal child; and this requires detailed knowledge of the range of symptoms with upper respiratory infections in the normal child. ${ }^{5}$

Overdiagnosis of asthma clearly matters. The fiscal cost of asthma medications is not trivial. Inhaled corticosteroids (ICS), when properly used, drastically improve quality of life and reduce the risk of asthma attacks and mortality. However they have side effects, including adrenal failure and growth suppression, with increasingly worrying evidence (mainly in adults) that they cause mucosal immunosuppression and an increased risk of respiratory infections. ${ }^{6}$ There is also evidence that systemic absorption of ICS depends not just on the prescribed dose, but is greater if the dose is inappropriately high for the degree of airway inflammation. ${ }^{7}$ The National Review of Asthma Deaths ${ }^{8}$ highlights another reason why we need to get the diagnosis right. It is an intensely depressing document which shows that no lessons have been learnt over the last 15 years, and children still

\footnotetext{
${ }^{1}$ Royal Brompton Harefield NHS Foundation Trust, London, UK; ${ }^{2}$ Imperial College, National Heart and Lung Institute, London, UK

Correspondence to Professor Andrew Bush, Department of Paediatric Respiratory Medicine, Royal Brompton Hospital, Sydney Street, London SW3 6NP, UK; a.bush@imperial.ac.uk
}

die because of failures in basic management. We propose that one contributing factor is that the diagnosis of asthma has been trivialised and inhalers dispensed for no good reason, and have become almost a fashion accessory. The result is the fact that asthma is a killing disease, if not correctly managed, is overlooked.

On this background, the National Institute for Health and Care Excellence (NICE) has put out a consultation paper recommending that we should seek more objective evidence before making a diagnosis of asthma. ${ }^{9}$ Disappointingly, the idea that asthma may be overdiagnosed and objective tests should be performed has not been uniformly welcomed. We have previously proposed a practical algorithm based on NICE's recommendation for the diagnosis of asthma incorporating objective tests. ${ }^{10}$ We know that the word wheeze, the hallmark symptom of asthma, is used imprecisely by parents and professionals. ${ }^{11}$ Is there any other chronic disease in the world in which children are committed to potentially hazardous, longterm therapy without every effort being made objectively to document the diagnosis? Of course, recommendations must be practical; it is unlikely that primary care and much of secondary care will be measuring exhaled nitric oxide (FeNO) any time soon, and it would be absurd to draw the conclusion that only tertiary care can diagnose paediatric asthma. However what should not be controversial are two principles:

A. We must seek evidence of variable airflow obstruction, at least in schoolage children, before contemplating an asthma diagnosis.

B. If therapeutic trials of treatment are to be performed, then they should be focused, and children should not be left on an unproven treatment ad infinitum.

Objective tests broadly relate to the diagnosis of variable airflow obstruction, and the characterisation of any airway inflammation that may be present. Physiological testing in the school-age child is available at all levels of care. The easiest is to measure peak flow at the point of care, and measure the acute response to a short-acting $\beta-2$ agonist (SABA). There will be none if peak flow is normal, but a simple exercise challenge test could be considered, although with the realisation that such field tests may lack specificity. ${ }^{12}$ Home peak flow meters are notoriously underused by children in the long term, but a two-week trial should be practical. ${ }^{13}$ It is totally legitimate for the child to have access to SABAs via an appropriate device during this period, and this provides an opportunity to see if there is fluctuation in peak flow either spontaneously or with SABA. Such testing is known to be specific but lacks sensitivity; the harder the paediatrician tries to demonstrate variable airflow obstruction, and the more this is not seen, the less likely is a diagnosis of asthma.

Thus far physiology has been addressed, but what about airway inflammation? ICS are an excellent treatment for eosinophilic airway inflammation, but if this is not present, should they be prescribed? Where does FeNO fit into the picture, if the measurement is available? First, atopy without asthma causes an elevation of $\mathrm{FeNO}^{14}$ it is not an asthma diagnostic test. Knowledge of whether the child is atopic is useful; if a school-age child is not atopic, eosinophilic airway inflammation is unlikely, but not impossible. However, FeNO is not needed to diagnose atopy; skin prick tests to common aeroallergens are more than sufficient. Second, in ICS-naive patients with asthma, FeNO correlates with airway eosinophilia. ${ }^{15}$ Hence if FeNO is available and normal, this means a diagnosis of asthma characterised by eosinophilic airway inflammation, and therefore being ICS-responsive, is unlikely. If FeNO is elevated, then ICS-responsive asthma may be present, but this is not certain.

An alternative surrogate for eosinophilic airway inflammation is peripheral blood eosinophilia. ${ }^{16}$ Careful interpretation is needed; blood eosinophilia may be driven by extrapulmonary atopic disease such as eczema, but a normal blood eosinophilia is another pointer that airway eosinophilia is unlikely. ${ }^{17}$

Blind therapeutic trials are another trap for the unwary. We suggest they should only be carried out when objective measurements cannot be made, and then too in a very focused manner. There is no evidence base, but we suggest a trial period of a moderate dose of ICS (eg, $200 \mu \mathrm{g}$ beclomethasone equivalent twice daily) for no more than 6 weeks, at the end of which, irrespective of the clinical state, treatment is stopped. If there has been no response, and (a big if!) if treatment has really been given, the diagnosis of asthma with eosinophilic inflammation can be discarded. If symptoms have disappeared and only if they subsequently reappear 
and again respond to ICS should a diagnosis of asthma be made, and ICS treatment titrated to the lowest effective dose. This staged trial avoids the paediatrician mistaking spontaneous improvement for therapeutic benefit. ${ }^{18}$

A further safeguard is to consider the diagnosis of asthma as dynamic-many children outgrow their symptoms, and many professors frequently get things wrong. No matter who has made the diagnosis, always consider whether it was actually correct in the first place, or whether it is still relevant. Asthma therapy should not be escalated heedlessly if there is no response-for most children, the plateau of the ICS dose-response curve is as low as $100 \mu \mathrm{g}$ fluticasone twice daily. ${ }^{19}$ Oliver Cromwell's advice is still apposite: 'I beseech you, in the bowels of Christ, think it possible that you may be mistaken'. 20

The present proposals by NICE are welcome in principle, but there are still many gaps which we should not tolerate. We need to move the diagnostic process forward in a number of ways. First, we need to bring objective testing into the preschool years; off-line FeNO, multiple breath washouts ${ }^{21}$ and even induced sputum $^{22}$ can all be performed, and surely should be performed, in nonstraightforward airway disease in this age group. Second, we should be more objective about therapeutic trials; they should be placebo-controlled, cross-over, $\mathrm{N}$ of 1 trials, during which neither the paediatrician nor the family know whether the active canister is being used. If we can obtain placebo inhalers for randomisedcontrolled trials and for Respiratory Nurses to demonstrate inhaler technique, why not for therapeutic trials? Electronic monitoring of adherence and peak flow measurements is surely the 21 st century gold standard, and adherence monitoring should move beyond whether the device has been activated to measuring whether someone has actually inhaled adequately from the device. Finally, we need to go beyond umbrella labels for airway diseases such as asthma, and move to phenotyping childhood airway diseases in terms of parameters such as fixed and variable airflow obstructions, presence or otherwise, and nature of, airway inflammation, and whether there is chronic infection. The aim is not to split and phenotype for the sake of it, but to identify treatable characteristics and treat them appropriately. ${ }^{23}$ But that is another story.

Contributors $A B$ wrote the first draft, $A B$ and $L F$ edited it, and both assume full responsibility for the manuscript.

\section{Competing interests None declared.}

Provenance and peer review Commissioned; externally peer reviewed.

$A B$ was supported by the NIHR Respiratory Disease Biomedical Research Unit at the Royal Brompton and Harefield NHS Foundation Trust and Imperial College London.

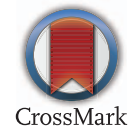

To cite Bush A, Fleming L. Arch Dis Child 2016:101:688-689.

Received 22 December 2015

Revised 13 February 2016

Accepted 17 February 2016

Published Online First 5 April 2016

Arch Dis Child 2016;101:688-689.

doi:10.1136/archdischild-2015-309053

\section{REFERENCES}

1 Martin Luther. Werke 1883;54;111.

2 Marchant JM, Masters IB, Taylor SM, et al. Evaluation and outcome of young children with chronic cough. Chest 2006;129:1132-41.

3 Kelly YJ, Brabin BJ, Milligan PJ, et al. Clinical significance of cough and wheeze in the diagnosis of asthma. Arch Dis Child 1996;75:489-93.

4 Ferreira Fde A, Filho LV, Rodrigues JC, et al. Comparison of atopic and nonatopic children with chronic cough: bronchoalveolar lavage cell profile. Pediatr Pulmonol 2007;42:857-63.

5 Thompson M, Vodicka TA, Blair PS, et al. TARGET Programme Team. Duration of symptoms of respiratory tract infections in children: systematic review. BMJ 2013;347:f7027.

6 Sabroe I, Postma D, Heijink I, et al. The yin and the yang of immunosuppression with inhaled corticosteroids. Thorax 2013;68:1085-7.
7 Brutsche $\mathrm{MH}$, Brutsche IC, Munawar M, et al. Comparison of pharmacokinetics and systemic effects of inhaled fluticasone propionate in patients with asthma and healthy volunteers: a randomised crossover study. Lancet 2000;356:556-61.

8 https://www.rcplondon.ac.uk/projects/national-reviewasthma-deaths

9 http://www.nice.org.uk/guidance/gid-cgwave0640/ resources/asthma-diagnosis-and-monitoring-draftnice-guideline2

10 Bush A, Fleming L. Diagnosis and management of asthma in children. BMJ 2015;350:h996.

11 Levy ML, Godfrey S, Irving CS, et al. Wheeze detection: recordings vs. assessment of physician and parent. J Asthma 2004;41:845-53.

12 Powell CV, White RD, Primhak RA. Longitudinal study of free running exercise challenge: reproducibility. Arch Dis Child 1996;74:108-14.

13 Redline S, Wright EC, Kattan M, et al. Short-term compliance with peak flow monitoring: results from a study of inner city children with asthma. Pediatr Pulmonol 1996;21:203-10.

14 Franklin PJ, Taplin R, Stick SM. A community study of exhaled nitric oxide in healthy children. Am J Respir Crit Care Med 1999;159:69-73.

15 Piacentini GL, Bodini A, Costella S, et al. Exhaled nitric oxide and sputum eosinophil markers of inflammation in asthmatic children. Eur Respir J 1999; 13:1386-90.

16 Price DB, Rigazio A, Campbell JD, et al. Blood eosinophil count and prospective annual asthma disease burden: a UK cohort study. Lancet Respir Med 2015;3:849-58.

17 McKeown S, Saglani S, Bush A, et al. The relationship between invasive and non-invasive measures of inflammation in children with severe, therapy-resistant asthma. Thorax 2015;70(Suppl 3): A124-5.

18 Bush A. Diagnosis of asthma in children under five. Prim Care Respir J 2007;16:7-15.

19 Lemanske RF Jr, Mauger DT, Sorkness CA, et al. Childhood Asthma Research and Education (CARE) Network of the National Heart, Lung, and Blood Institute. Step-up therapy for children with uncontrolled asthma receiving inhaled corticosteroids. N Engl J Med 2010;362:975-85.

20 Carlyle T, ed. Oliver Cromwell's letters and speeches 1. New York: Harper, $1855: 448$.

21 Ahmad F, Irving $S$, Alton E, et al. Multiple breath washouts in children can be shortened without compromising quality. Eur Respir J 2015:46:1814-16.

22 Zar HJ, Hanslo D, Apolles P, et al. Induced sputum versus gastric lavage for microbiological confirmation of pulmonary tuberculosis in infants and young children: a prospective study. Lancet 2005:365:130-4.

23 Bush A, Kleinert S, Pavord ID. The asthmas in 2015 and beyond: a Lancet Commission. Lancet 2015;385:1273-5. 